Rev. Inst. Flor. v. 29 n. 1 p. $7-17$ jun. 2017

http://dx.doi.org/10.24278/2178-5031.201729101

ISSN impresso 0103-2674/on-line 2178-5031

\title{
REGIÕES COM POTENCIAL CLIMÁTICO PARA PLANTIO COMERCIAL DO GUANANDI NO BRASIL ${ }^{1}$
}

\section{REGIONS WITH CLIMATIC POTENTIAL FOR COMMERCIAL PLANTING OF GUANANDI IN BRAZIL}

\author{
Marcos Silveira WREGE2,3; Elenice FRITZSONS²; \\ Antônio Nassim KALIL FILHO²; Ananda Virginia de AGUIAR ${ }^{2}$
}

\begin{abstract}
RESUMO - O guanandi, nativo do Brasil, é uma espécie com usos múltiplos, produz madeira de excelente qualidade, muito apreciada no mercado e constitui excelente alternativa ao cultivo do mogno e cedro rosa. É uma espécie muito boa para uso em plantios visando ao reflorestamento ambiental, inclusive na recomposição de florestas ciliares, pelo fato de ser muito procurada pela fauna e por suportar terrenos com nível freático elevado. Apesar das inúmeras vantagens, há poucas informações sobre a espécie, havendo necessidade de aprofundar os estudos, inclusive os relativos ao zoneamento climático. O presente trabalho é importante para auxiliar no planejamento de uso da terra, servindo de base para estudos de zoneamento agrícola de riscos climáticos, importante instrumento de política agrícola para concessão de seguro rural e crédito agrícola. A identificação das regiões com os menores riscos climáticos é ferramenta essencial para auxiliar produtores rurais a conduzirem suas atividades com maior êxito, ao escolher, para cada região, a cultura mais bem adaptada. A geada e a deficiência hídrica são responsáveis pela maioria dos sinistros agrícolas no país, ocasionando perdas econômicas por longos períodos. Assim, este estudo apresenta as diferentes zonas climáticas existentes no Brasil para o cultivo comercial do guanandi, por meio das informações geoespaciais de risco de ocorrência de geadas e de déficit hídrico, mapeadas utilizando SIG. As melhores zonas para o plantio comercial do guanandi foram aquelas com baixos riscos de geada, associadas a um balanço hídrico favorável, o que ocorre em grande parte do Brasil, principalmente na região amazônica e na costa brasileira.
\end{abstract}

Palavras-chave: zoneamento agrícola; riscos climáticos; planejamento de uso da terra.

\begin{abstract}
Guanandi is a woody species native to Brazil with multiple uses, it has a wood of excellent quality, much appreciated in the market and it is a good alternative for the cultivation of mahogany and pink cedar. It is a very good species for use in plantations aiming to the environmental reforestation, including the recomposition of riparian forests, due to the fact that it is very much sought after by the fauna and to support terrains with high water table. Despite the many advantages, there is little information about the species, and there is a need to deepen the studies, including those related to climatic zoning.
\end{abstract}

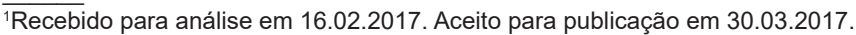


The present work is important to assist in land use planning, serving as a basis for agricultural zoning studies of climatic risks, an important agricultural policy instrument for granting rural insurance and agricultural credit. The identification of regions with the lowest climate risks is an essential tool to help rural producers to conduct their activities with greater success, by choosing for each region the best adapted crop. Frost and water deficiency are responsible for most agricultural claims in the country, leading to economic losses. Thus, this study presents the different climatic zones in Brazil suitable for the commercial cultivation of guanandi, identified through the geospatial information of risk of frost occurrence and water deficit, mapped using GIS. The best areas for the guanandi commercial plantation were those with low frost risks associated with a favorable water balance. These conditions occur in much of Brazil, mainly in the Amazon region and on the Brazilian coast.

Keywords: climatic zoning; climatic risks; land use planning.

\section{INTRODUÇÃO}

O guanandi, Calophyllum brasiliense Cambessèdes, espécie nativa do Brasil, pertence à família Calophyllaceae (Neri, 2011), gênero Calophyllum, que compreende aproximadamente 190 espécies, sendo que somente oito delas ocorrem na América Central e América do Sul (Soerianegara e Lemmens, 1993).

Possui ampla distribuição geográfica, ocorrendo desde a região amazônica até o norte de Santa Catarina, nas florestas Amazônica e Atlântica, sendo comum também em florestas no domínio do Cerrado. Apesar de sua plasticidade ecológica (Kawaguici e Kageyama, 2001), a ocorrência de $C$. brasiliense está sempre associada a solos úmidos ou brejosos (Oliveira-Filho e Ratter, 1995), podendo ser encontrada tanto em florestas primárias densas como em vários estágios da sucessão secundária, entre eles capoeiras e capoeirões (Lorenzi, 1998; Marques e Joly, 2000).

Ocorre desde o México até a América do Sul, sempre em planícies com inundações temporárias (Carvalho, 2003). Possui facilidade de regeneração natural e apresenta-se, não raro, como uma das espécies dominantes, formando os guanandizais ou olandizais.

Tem múltiplas aplicações, possuindo madeira de qualidade muito boa, além de haver uso ainda para sua casca e para o óleo extraído das sementes. Pode ser usada como alternativa, substituindo o mogno e o cedro, que têm problemas com a broca (Hypsipyla grandella), a qual inviabiliza os plantios comercias de ambos.
C. brasiliense não tolera geadas e apresenta melhor crescimento em solos bem drenados, no entanto suporta bem os solos brejosos. Por esse motivo, a drenagem dos solos não é fator limitante. Sua produtividade, medida pelo Incremento Médio Anual - IMA, varia de pouco mais de $8 \mathrm{~m}^{3} \mathrm{ha}^{-1}$ ano $^{-1}$, na região Norte do Brasil (Manaus, AM), a $18 \mathrm{~m}^{3} \mathrm{ha}^{-1} \mathrm{ano}^{-1}$, na Costa Rica. É espécie heliófila, com crescimento monopodial e desrama natural fraca, necessitando de poda dos galhos. É encontrada tanto em floresta primária densa como em vários estágios de sucessão secundária, entre eles capoeiras e capoeirões (Lorenzi, 2002).

Em áreas degradadas, onde espécies introduzidas, como o eucalipto e o pinus, podem não apresentar um bom desenvolvimento, é necessária a exploração de espécies nativas, entre as quais o guanandi. Mas, devido à grande carência de informações, os plantios comerciais são estabelecidos com espécies dos gêneros Eucalyptus, Pinus e Tectona (Evans, 1992), espécies que compõem a maior parte dos reflorestamentos na América Latina, estimado em 11,1 milhões de hectares (Keipi, 1999).

As características que fazem do guanandi uma espécie interessante e com potencial para exploração comercial são: madeira leve a moderadamente densa $\left(0,60\right.$ a $\left.0,75 \mathrm{~g} \mathrm{~cm}^{-3}\right)$, com retratabilidade e resistência mecânica médias e estabilidade dimensional média, superfície ligeiramente lustrosa, boa durabilidade e resistência, o que permite seu uso na construção civil e naval, na produção de cabos de ferramentas, móveis finos, dormentes, pontes, postes, chapas, lâminas faqueadas decorativas, barris para depósito de vinhos e 
para trabalhos gerais de carpintaria e marcenaria (Carvalho, 2003). É moderadamente durável à podridão branca e marrom e imputrescível dentro da água, sendo utilizada em outros países da América do Sul como alternativa ao mogno e ao cedro. A espécie apresenta ainda potencial medicinal, com vários usos (Isaias et al., 2004; Noldin et al., 2006; Huerta-Reyes et al., 2004; Noldin et al., 2006).

O guanandi tem madeira bastante valorizada, muito acima das madeiras de Pinus e Eucalyptus. Além disso, é uma espécie que pode ser encontrada em diversas regiões do Brasil pela sua ampla distribuição geográfica, ocorrendo no Amazonas (Ayres, 1995), Bahia (Stannard, 1995), Espírito Santo (Jesus, 1998), Goiás (Ramos e Imaña-Encinas, 2000), Mato Grosso (Pasa et al., 2000), Mato Grosso do Sul (Souza et al., 1997), Minas Gerais (Carvalho et al., 2003), Pará (Montagnini e Muniz-Miret, 1997), Paraná (Souza et al., 1997), Rio de Janeiro (Barros e Callado, 1997), Santa Catarina (Klein, 1969) e São Paulo (Durigan et al., 1999).

O presente estudo é importante para auxiliar no planejamento de uso da terra, servindo de base para estudos de zoneamento agrícola de riscos climáticos, os quais são importantes instrumentos de política agrícola para concessão de seguro rural e crédito agrícola. A identificação das regiões com os menores riscos climáticos é ferramenta essencial para auxiliar produtores rurais a conduzirem suas atividades com maior êxito, ao escolherem, para cada região, a cultura mais bem adaptada. A geada e a deficiência hídrica são responsáveis pela maioria dos sinistros agrícolas no país, ocasionando perdas econômicas por longos períodos.

O objetivo deste trabalho foi realizar um estudo de mapeamento das diferentes zonas climáticas no país para o cultivo comercial do guanandi, indicando as melhores regiões para seu cultivo comercial, por meio das informações geoespaciais de risco de ocorrência de geadas, analisado em conjunto com o balanço hídrico, utilizando para isso sistemas geográficos de informações.

\section{MATERIAL E MÉTODOS}

O risco de geadas é um dos grandes problemas para uso do guanandi em plantio comercial. As geadas são comuns nas regiões Sul, Sudeste e parte do Centro-Oeste do Brasil. Neste trabalho, usou-se o risco de ocorrência de geadas como critério de delimitação de zonas para plantio dessa espécie nos estados da região Sul do Brasil e para os estados de São Paulo e Minas Gerais.

Os riscos de geada foram estabelecidos usando a série temporal de dados climáticos fornecidos pelos institutos estaduais de pesquisa do Paraná e do Rio Grande do Sul (Instituto Agronômico do Paraná - IAPAR e Fundação Estadual de Pesquisa Agropecuária - FEPAGRO), na qual existem dados diários do período-base 1976-2005. Foram usados dados de temperatura mínima do ar e foram calculadas as frequências com temperaturas do ar inferiores a $3{ }^{\circ} \mathrm{C}$ no mês mais frio do ano (julho). A frequência foi calculada da seguinte maneira (Equação 1; Tabela 1):

frequência de geadas $=(\mathrm{n} / 10) \times 100 \quad($ Equação 1$)$

Em que:

n: número de dias, a cada 10 dias, em que a temperatura mínima do ar atinge menos de $3{ }^{\circ} \mathrm{C}$ no abrigo meteorológico.

Utilizou-se a temperatura mínima do ar de $3{ }^{\circ} \mathrm{C}$ no abrigo meteorológico (Grodzki et al., 1996) (situado a 1,5 metro de altura), considerando-se que a mesma está relacionada à ocorrência de geadas, devido ao fenômeno de inversão térmica que ocorre em noites estáveis de inverno, ocasionando um gradiente médio de temperatura entre o abrigo e a relva superior a $4{ }^{\circ} \mathrm{C}$ (Silva e Sentelhas, 2001).

Por meio de análise de regressão, os riscos de geadas foram calculados e correlacionados com o modelo do terreno (altitude) e aos modelos de coordenadas geográficas decimais. A equação foi usada em sistema de informações geográficas para mapear os riscos de ocorrência de geadas, calculados a partir de dados organizados e compilados para a região Sul do país por Wrege et al. (2011). Os riscos de geadas também foram calculados para o estado de São Paulo a partir da base de dados do Sul do país, pelo fato de se situar em uma faixa de latitude muito próxima à do Paraná, de acordo com metodologia usada por Wrege et al. (2014). 
WREGE, M.S. et al. Regiões para plantio do guanandi.

O modelo do terreno usado foi o GTOPO30, o qual reproduz as cotas altimétricas do Brasil, elaborado pelo serviço geológico dos Estados Unidos (United States Geological Survey, 2011), a partir de imagens de radar. Foram produzidos, também, modelos dos paralelos e dos meridianos, representando o efeito de continentalidade. Os modelos reproduzem a latitude e a longitude do Brasil, na escala 1:250.000, do mesmo modo que o modelo do terreno.
Para as demais regiões do Brasil, foram adotados outros critérios, pelo fato das restrições climáticas serem diferentes. Utilizou-se, assim, o balanço hídrico climático (P-ETP), em que P é o total de precipitação pluviométrica de um mês (mm) e ETP é a evapotranspiração potencial acumulada em um mês $(\mathrm{mm})$, calculada pelo método de Thornthwaite (Thornthwaite, 1948), segundo metodologia feita por Wrege et al. (2011). Utilizou-se a base de dados gerados por Hamada et al. (2008).

Tabela 1. Coeficientes da equação de regressão linear múltipla dos riscos de geada para os estados de São Paulo, Paraná, Santa Catarina e Rio Grande do Sul.

Table 1. Coefficients of multiple linear regression of frost risk in the states of São Paulo, Paraná, Santa Catarina and Rio Grande do Sul.

\begin{tabular}{lcccc}
\hline \multirow{2}{*}{ Estados } & \multicolumn{4}{c}{ Coeficientes da equação de regressão } \\
\cline { 2 - 4 } & $-2,8864$ & $\beta$ & $\chi$ & $\delta$ \\
\hline São Paulo e Paraná & $-0,1081$ & $-0,004937$ & 0,0005165 \\
\hline $\begin{array}{l}\text { Santa Catarina e } \\
\text { Rio Grande do Sul }\end{array}$ & $-2,6701$ & $-0,09784$ & 0,001844 & 0,0004057 \\
\hline
\end{tabular}

Foram somadas as diferenças de P-ETP de cada mês para cada local, totalizando o valor de P-ETP para um ano completo. Quando o valor final foi superior a $400 \mathrm{~mm}$, o local foi considerado favorável para plantio comercial do guanandi em relação à disponibilidade hídrica; quando se situava entre $0-400 \mathrm{~mm}$, indicava que o local era considerado marginal e, quando foi inferior a $0 \mathrm{~mm}$, foi considerado indicativo de condição desfavorável ao plantio comercial.

O mapa do balanço hídrico climático foi elaborado usando-se geoestatística, por meio de krigagem por indicação, em que são relacionados os pontos dos locais de ocorrência de cada uma das estações pertencentes à rede de estações meteorológicas com os pontos das estações vizinhas.

Os mapas dos limites estaduais e do limite federal usados foram os do Instituto Brasileiro de Geografia e Estatística - IBGE (2001), que são os mapas oficiais do Brasil.

Os mapas foram classificados, delimitando-se as zonas pelos riscos de geadas e de disponibilidade hídrica, necessários ao desenvolvimento do guanandi, citados anteriormente.

\section{RESULTADOS E DISCUSSÃO}

Existem poucas informações sobre o guanandi e, até o momento, não existe documento de orientação sobre as melhores regiões para plantio comercial da espécie no Brasil. Este, portanto, é o primeiro documento orientador, contendo mapas das regiões indicadas para plantio comercial com menores riscos climáticos no país.

Os fatores mais importantes a se considerar na definição de zonas com baixos riscos climáticos para plantio de guanandi, no Brasil, são os riscos de geadas e o balanço hídrico, conforme ocorre com a maioria das espécies comerciais cultivadas no país e os zoneamentos agrícolas feitos para essas espécies, indicando as melhores regiões para plantio (Wrege et al., 2014; Fritzsons et al., 2012). Assim, para o desenvolvimento do guanandi, os riscos de geada devem ser inferiores a $10 \%$, o que representa, na média, uma geada a cada 10 anos. 
O déficit hídrico não restringe o desenvolvimento da espécie, mas pode ser responsável por reduzir o porte da vegetação e a produtividade, prolongando o tempo para produção e tornando inviável o cultivo comercial nas regiões em que os riscos de estiagem forem muito severos. Pode ser um problema maior nos dois primeiros anos de cultivo, mas as espécies florestais, de modo geral, são capazes de aprofundar o sistema radicular e buscar água em profundidade, o que é mais raro para espécies de ciclo anual de desenvolvimento.
Neste trabalho, definiu-se como crítica a diferença entre precipitação e a evapotranspiração abaixo de $400 \mathrm{~mm}$ (Figura 1). Associando-se os dois fatores, risco de geadas e o balanço hídrico, obteve-se áreas favoráveis ao cultivo comercial do guanandi, que são bastante extensas (Figura 2), em função da grande plasticidade ecológica da espécie (Kawaguici e Kageyama, 2001), que tem possibilidade de cultivo nas regiões de clima tropical, como é o caso da Amazônia e da zona costeira do Sul do país, incluindo o litoral do Paraná e de Santa Catarina.

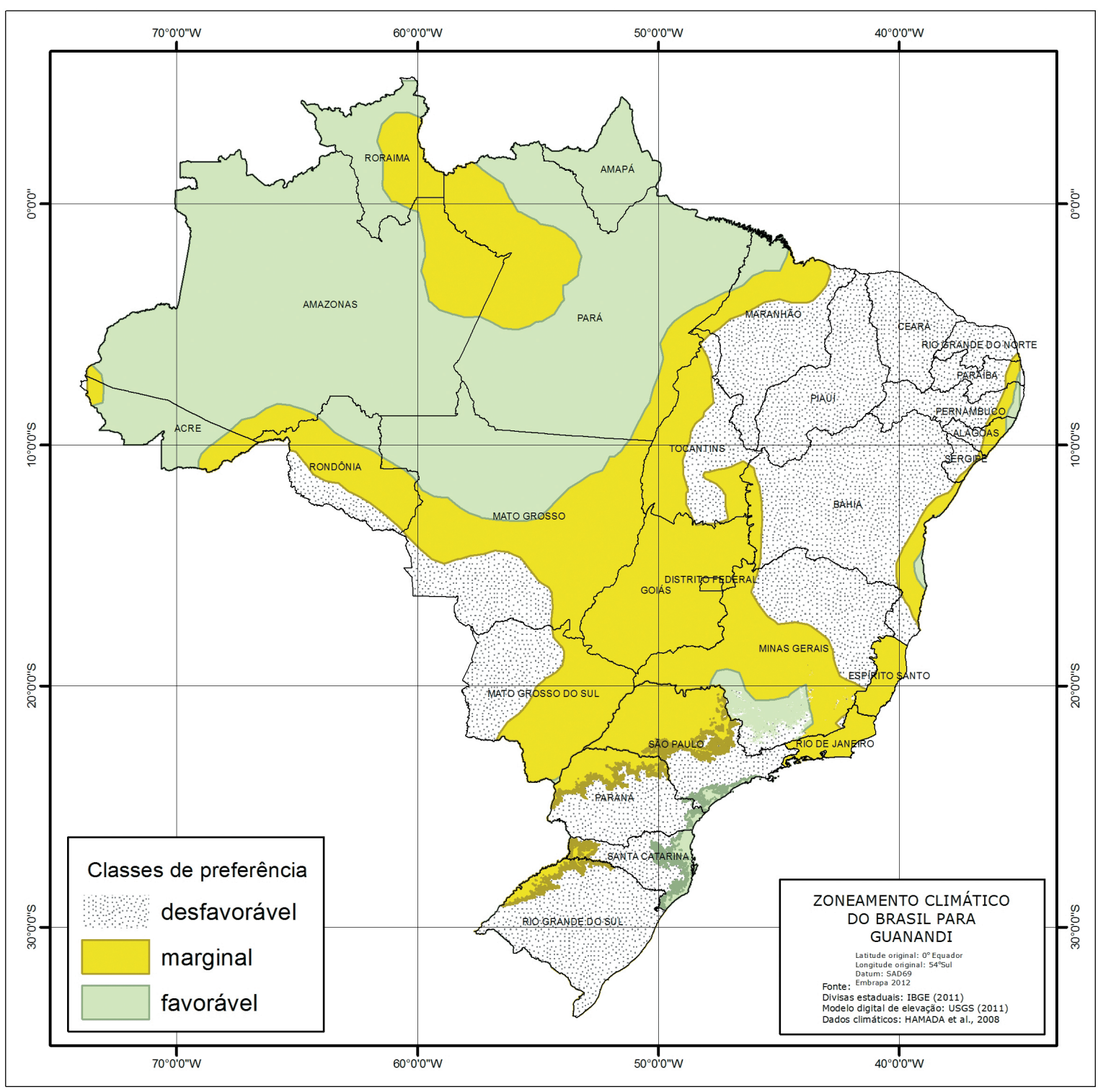

Figura 1. Delimitação de regiões favoráveis para plantio comercial de guanandi no Brasil.

Figure 1. Delineation of favorable areas for commercial planting of guanandi in Brazil. 


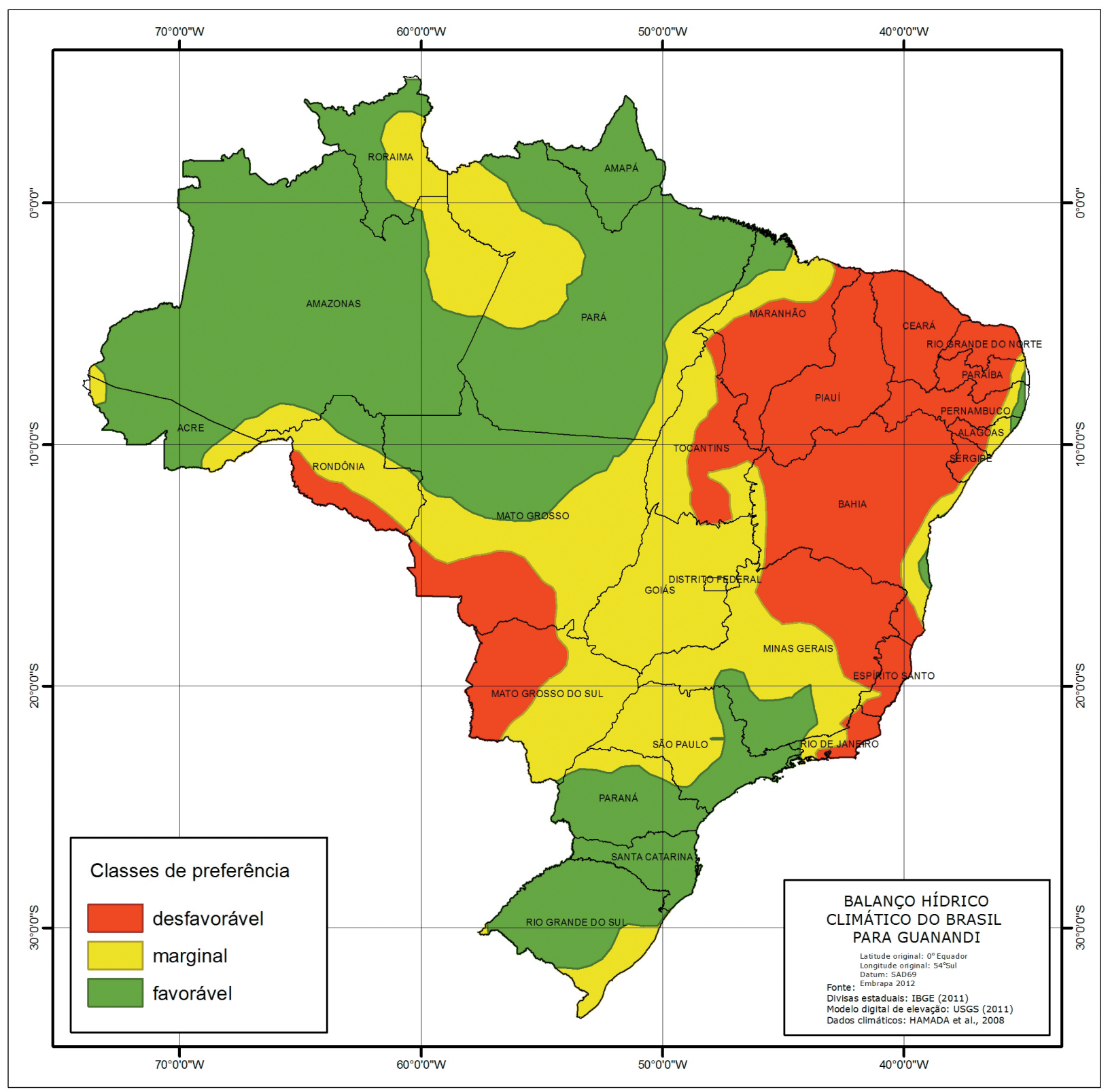

Figura 2. Classes de preferência para plantios comerciais de guanandi no Brasil, caracterizadas pelo balanço hídrico climático (P-ETP).

Figure 2. Classes of preference for commercial guanandi planting in Brazil, characterized by climatic water balance (P-ETP).

No Sul do país, onde o clima subtropical é predominante, a espécie pode ser cultivada em algumas regiões onde os riscos de geadas são menores (figuras 3 a 5). Em quase toda a região, o balanço hídrico é favorável para o desenvolvimento do guanandi (Wrege et al., 2011). Assim, as zonas litorâneas dos estados do Paraná e de Santa Catarina são favoráveis, pois possuem clima subtropical/tropical, em que as temperaturas, totais pluviométricos e umidade relativa do ar são maiores, praticamente sem ocorrência de geadas e de períodos de estiagem. O guanandi, inclusive, ocorre espontaneamente como espécie pioneira nas formações de influência fluvial do litoral paranaense (Carvalho, 2003). 
WREGE, M. S. et al. Regiões para plantio do guanandi.

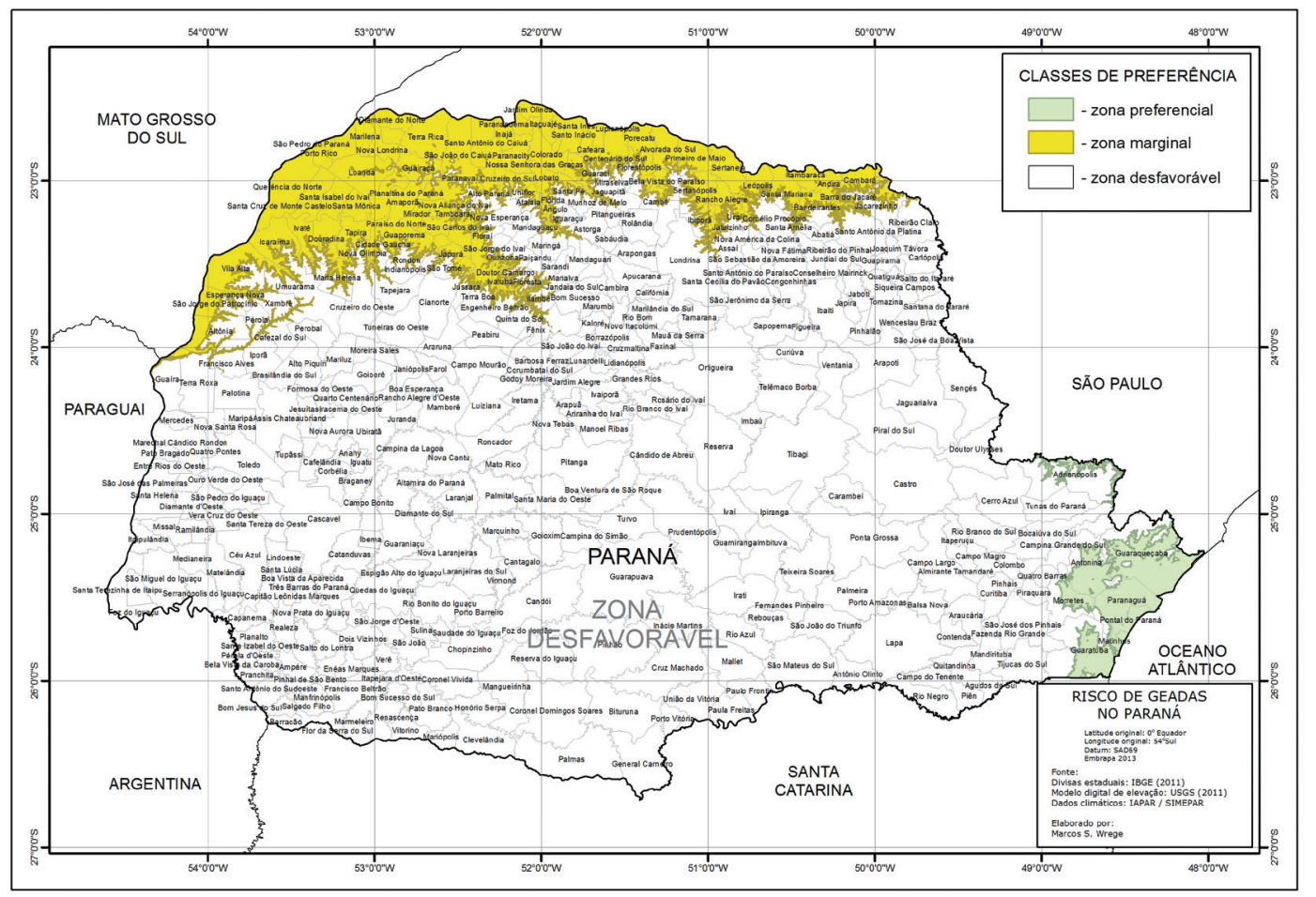

Figura 3. Delimitação das zonas favoráveis para plantio de guanandi no estado do Paraná quanto aos riscos de geada.

Figure 3. Delineation of favorable areas for planting guanandi in the state of Paraná according to the risks of frost.

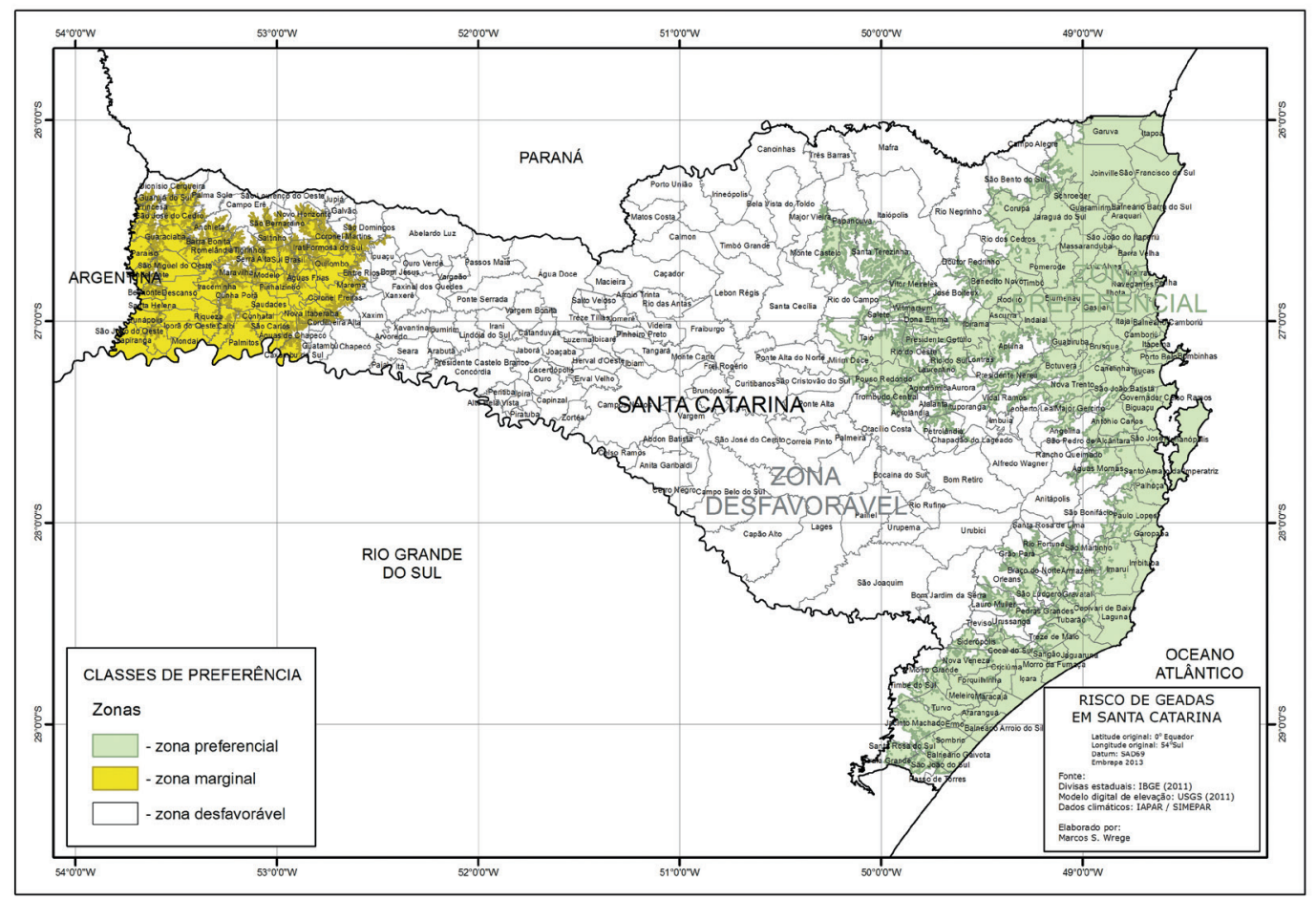

Figura 4. Delimitação das zonas favoráveis para plantio de guanandi no estado de Santa Catarina quanto aos riscos de geada.

Figure 4. Delineation of favorable areas for planting guanandi in the state of Santa Catarina according to the risks of frost. 


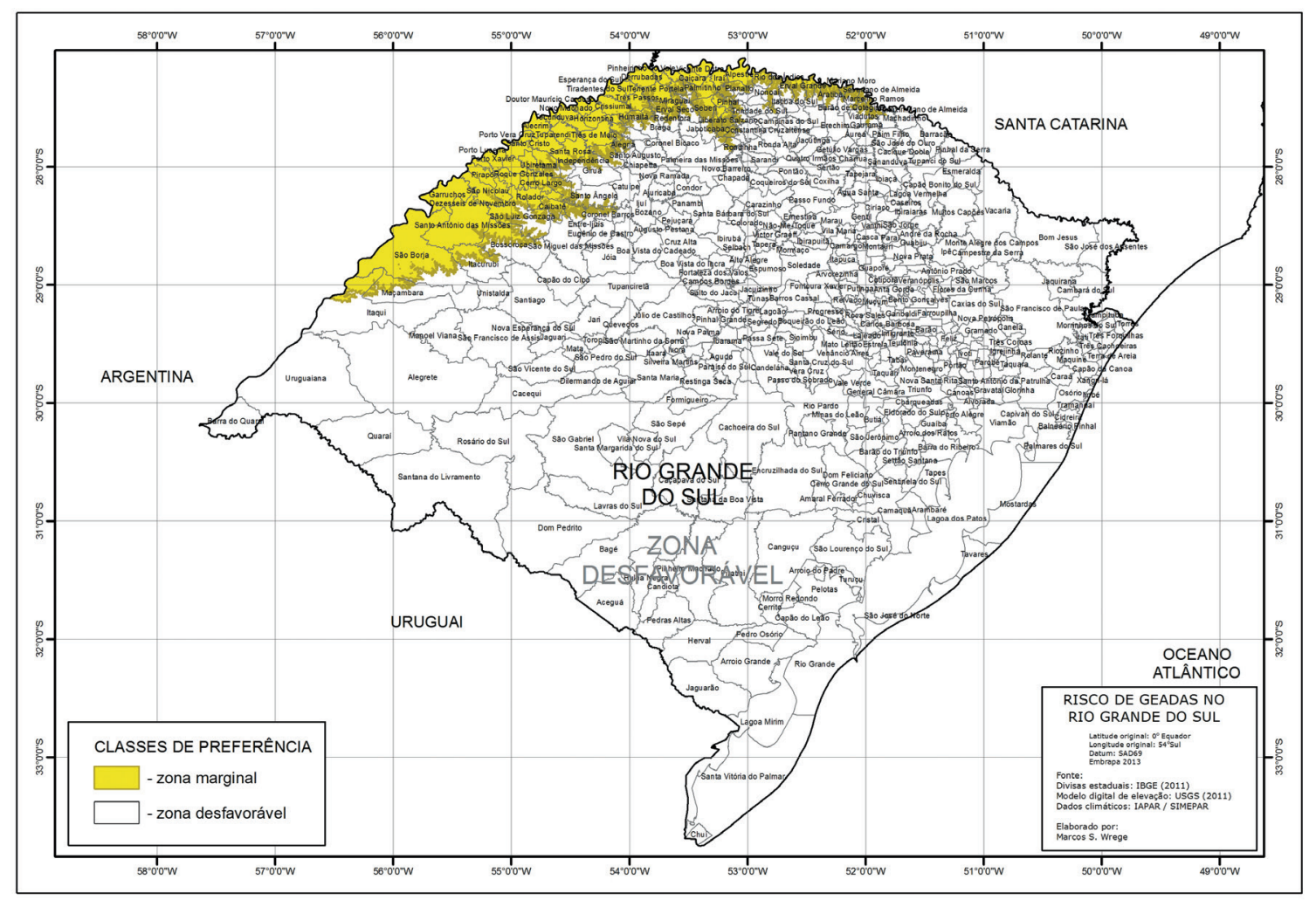

Figura 5. Delimitação das zonas favoráveis para plantio de guanandi no estado do Rio Grande do Sul quanto aos riscos de geada.

Figure 5. Delineation of favorable areas for planting guanandi in the state of Rio Grande do Sul according to the risks of frost.

O sudoeste do Paraná, oeste de Santa Catarina e noroeste do Rio Grande do Sul são zonas representadas por grandes totais pluviométricos e, portanto, apresentam as maiores disponibilidades hídricas da região Sul do Brasil, totalizando, na média, quase $2.000 \mathrm{~mm}$ de chuva acumulada em um ano (Wrege et al., 2011). O oeste de Santa Catarina e o noroeste do Rio Grande do Sul são zonas com maiores temperaturas, mas que, apesar disso, são sujeitas a geadas (figuras 3, 4 e 5) e que, por esse motivo, não são recomendadas para o cultivo comercial do guanandi.

O sudoeste do Paraná apresenta grande variação espacial da temperatura (Figura 3). A região é sujeita à entrada de frentes frias, as quais aumentam os riscos de geada e trazem as chuvas vindas do Sul. O risco de geadas é maior inclusive nas zonas de menor altitude, como na foz do rio Iguaçu. A variação de temperatura também é decorrente do relevo de altitude, que tem forte influência na temperatura do ar. Essa região, portanto, também não é recomendada para cultivo comercial do guanandi. No estado, a região situada ao norte do trópico de Capricórnio, de clima tropical, é marginal para o estabelecimento de plantios comerciais de guanandi, por apresentar períodos de estiagem.

No Rio Grande do Sul, não há zona preferencial, sendo que a maior parte do estado é desfavorável para o desenvolvimento comercial da espécie, existindo apenas área marginal na região do Vale do Uruguai, onde predomina relevo de pequena altitude devido à calha do rio Uruguai e a temperatura, assim, é maior e o risco de geada, menor (Figura 5).

São Paulo (Figura 6) apresenta a maior área como marginal para o cultivo comercial do guanandi, sendo que na região centro-oeste do estado, as temperaturas do ar são maiores e o risco de geadas é menor $(<10 \%)$. Contudo, a região é de transição para o Cerrado e o total pluviométrico é reduzido, o que pode influenciar na produtividade dos cultivos comerciais. Nas zonas de maior altitude, superiores a $700 \mathrm{~m}$, o risco de geadas é maior ( $>10 \%$ ), uma vez que a temperatura diminui com a maior altitude, de acordo com o gradiente específico de cada local (Fritzsons et al, 2008), tornando o plantio comercial do guanandi uma atividade de risco. 


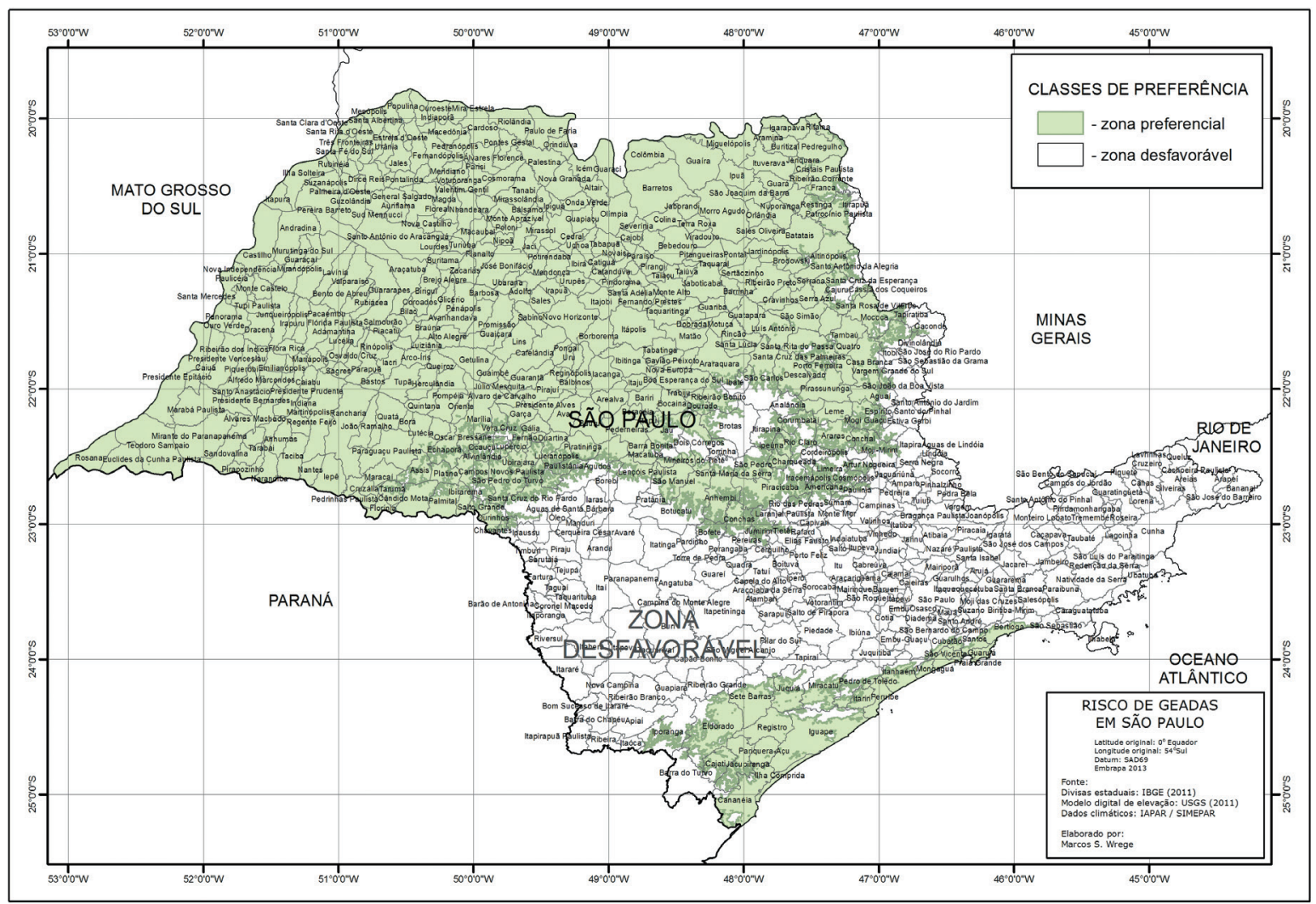

Figura 6. Delimitação das zonas favoráveis para plantio de guanandi no estado de São Paulo quanto aos riscos de geada.

Figure 6. Delineation of favorable areas for planting guanandi in the state of São Paulo according to the risks of frost.

Na região oeste de São Paulo, ocorrem restrições pelo aumento dos riscos de estiagem, assim como ocorre no noroeste do Paraná. A temperatura é favorável para o desenvolvimento do guanandi, em função da latitude e da menor altitude. Nessa região, marginal para o desenvolvimento da espécie em função da deficiência hídrica, os plantios precisam ser feitos com mudas vigorosas, no início da estação chuvosa, após o período de ocorrência de geadas.

Nas regiões Sul e Sudeste do Brasil, nos limites de transição das zonas favoráveis, ou marginais, para as desfavoráveis, são necessários cuidados maiores na implantação dos plantios, principalmente nas baixadas e fundos de vale, onde pode existir acúmulo de ar frio com a queda de temperatura nas horas mais frias do dia e zonas onde podem existir corredores de ventos frios. Nesses locais, de preferência, deve-se escolher as faces norte, noroeste ou nordeste, onde as temperaturas são maiores, evitando-se a face sul, sempre que possível.

Para reduzir os riscos de geada para o guanandi, deve-se realizar o transplantio preferencialmente após o período crítico de ocorrência de geadas.
O período crítico se estende entre maio e setembro na região Sul e de maio a agosto na região Sudeste.

Nos estados de Mato Grosso e Mato Grosso do Sul ainda chegam frentes frias, embora mais fracas que nas regiões Sul e Sudeste do país, representando baixo risco de geadas.

Nas regiões onde predominam o Cerrado e o clima Semiárido, ocorrem períodos de estiagem severa capazes de reduzir a produção das espécies florestais. Na região amazônica, onde ocorre maior precipitação, o volume total pluviométrico é variável, ocorrendo menos chuvas no leste de Roraima, nordeste do Amazonas e noroeste do Pará, com maiores riscos de estiagens.

Este trabalho é um estudo das zonas consideradas melhores, no aspecto climático, para o estabelecimento de plantios comerciais com guanandi. No entanto, é importante considerar que o êxito dos plantios comerciais dessa espécie depende não somente das boas condições climáticas, mas também de boas condições dos solos. A espécie normalmente aparece associada a solos úmidos e mal drenados, ocorrendo naturalmente nos brejos (Oliveira-Filho e Ratter, 1995). 


\section{CONCLUSÕES}

O guanandi pode ser usado para plantios comerciais em regime de silvicultura intensiva em algumas regiões do Brasil. Existem regiões que são mais adequadas para o plantio comercial. São aquelas onde o clima é mais quente, com menores riscos de ocorrência de geadas, onde as estiagens são menos frequentes e a disponibilidade hídrica é suficiente para atender à demanda da cultura, o que inclui a zona costeira do Sul do país.

No Sul do Brasil, a região costeira é a mais indicada para a silvicultura intensiva com o guanandi, representada pelas maiores temperaturas. Basicamente, não existe restrição, para o cultivo comercial, pelo déficit hídrico.

Nas demais regiões do país, onde as regiões são marginais por restrições hídricas, o plantio sempre deve ser feito no período da estação chuvosa, reduzindo os riscos de perdas causadas pela estiagem nos primeiros anos de cultivo.

$\mathrm{O}$ conhecimento existente atualmente sobre o guanandi é insuficiente para indicá-lo como alternativa ao plantio comercial de pinus e eucalipto, embora seu futuro pareça ser promissor, pois ainda são necessárias pesquisas mais avançadas, nas quais sejam desenvolvidas técnicas culturais que permitam maior produtividade com menor custo de produção.

\section{AGRADECIMENTOS}

Aos curadores do Museu Paraense Emílio Goeldi, Dra. Ione Bemerguy e Dr. Ricardo de Souza Secco, à pesquisadora Dra. Maria Lucia Absy e ao curador do Instituto Nacional de Pesquisas da Amazônia - INPA, Dr. Mike Hopkins, pelos dados de ocorrência do guanandi no Brasil.

\section{REFERÊNCIAS BIBLIOGRÁFICAS}

AYRES, J.M. As matas de várzea do Mamirauá: Médio Rio Solimões. 2. ed. Brasília, DF: CNPq; Tefé: Sociedade Civil Mamirauá, 1995. 123 p. (Estudos do Mamirauá, 1).

BARROS, C.F.; CALLADO, C.H. (Org.). Madeira da Mata Atlântica: anatomia do lenho de espécies ocorrentes nos remanescentes florestais do Estado do Rio de Janeiro - Brasil. Rio de Janeiro: Jardim Botânico do Rio de Janeiro, 1997. v. 1.
CARVALHO, P.E.R. Espécies arbóreas brasileiras. Brasília, DF: Embrapa Informação Tecnológica; Colombo: Embrapa Florestas. 2003. 1.039 p.

DURIGAN, G. et al. Regeneração natural de vegetação de cerrado sob floresta de Eucalyptus citriodora. Revista do Instituto Florestal, v. 9, n. 1, p. 71-85, 1999.

EVANS, J. Plantation forestry in the tropics. $2^{\text {nd }}$ ed. Oxford: Clarendon Press, 1992. 403 p.

FRITZSONS, E. et al. Zoneamento climático para plantio experimental de Pinus maximinoi no Estado de São Paulo. Pesquisa Florestal Brasileira, v. 32, p. 79-92, 2012.

;) MANTOVANI, L.E.; AGUIAR, A.V. Relação entre altitude e temperatura: uma contribuição ao zoneamento climático no Estado do Paraná. Revista de Estudos Ambientais, 2008. Disponível em: <http:/proxy.furb.br/ojs/index.php/rea/ article/view/902>. Acesso em: 14 maio 2013.

GRODZKI, L.; CARAMORI, P.H.; BOOTSMA, A. Risco de ocorrência de geada no Estado do Paraná. Revista Brasileira de Agrometeorologia, v. 4, n. 1, p. 93-99, 1996.

HAMADA, E. et al. Cenários climáticos futuros para o Brasil. In: GHINI, R.; HAMADA, E. (Org.). Mudanças climáticas: impactos sobre doenças de plantas no Brasil. Brasília, DF: Embrapa Informação Tecnológica, 2008. v. 1, p. 25-73.

HUERTA-REYES, M. et al. HIV-1 inhibitory compounds from Calophyllum brasiliense leaves. Biological Pharmacology Bulletin, v. 27, n. 9, p. 1471-1475, 2004.

INSTITUTO BRASILEIRO DE GEOGRAFIA E ESTATÍSTICA - IBGE. Malha municipal digital do Brasil: 2001. Rio de Janeiro, 2001. CD-rom.

JESUS, R.M. A reserva florestal de Porto Seguro. In: CONGRESSO FLORESTAL ESTADUAL, 6. 1988, Nova Prata. Anais... Nova Prata: Prefeitura Municipal de Nova Prata: Meridional, 1988. v. 1, p. 113-164.

KAWAGUICI, C.B.; KAGEYAMA, P.Y. Diversidade genética de três grupos de indivíduos (adultos, jovens e plântulas) de Calophyllum brasiliense em uma população de mata de galeria. Scientia Forestalis, v. 59, p. 131-143, 2001. 
WREGE, M. S. et al. Regiões para plantio do guanandi.

KEIPI, K. Introduction. Forest resource policy in Latin America. In: KEIPI, K. (Ed.). Inter-American Development Bank. Washington, D.C.: John Hopkins University Press, 1999. p. 1-10.

KLEIN, R.M. Árvores nativas da Ilha de Santa Catarina. Insula, n. 3, p. 3-93, 1969.

LORENZI, H. Árvores brasileiras: manual de identificação e cultivo de plantas arbóreas nativas do Brasil. Nova Odessa: Plantarum, 1998. 352 p.

Árvores brasileiras. Nova Odessa: Plantarum, 2002. 368 p.

MARQUES, M.C.M; JOLY, C.A. Estrutura e dinâmica de uma população de Calophyllum brasiliense Camb. em floresta higrófila do Sudeste do Brasil. Revista Brasileira de Botânica, v. 23, n. 1, p. 107-112, 2000.

MONTAGNINI, F.; MUNIZ-MIRET, N. Vegetación y suelos de las planicies inundables del estuário amazónico: una comparación de bosques de "varzea" y "terra firme" en Pará, Brasil. Agrotropica, v. 9, n. 3, p. 107-118, 1997.

NOLDIN, V.F.; ISAIAS, D.B.; CHINEL FILHO, V. Gênero Calophyllum: importância química e farmacológica. Química Nova, v. 29, n. 3, p. 549-554, 2006.

OLIVEIRA-FILHO, A.T.; RATTER, J.A. A study of the origin of Central Brazilian forests by the analysis of plants species distribution patterns. Journal of Botany, v. 52, n. 2, p. 141-194, 1995.

PASA, M.C. et al. Repertório etnobotânico do guanandi (Calophyllum brasiliense Camb. - Guttiferae). In: CONGRESSO NACIONAL DE BOTÂNICA, 51., 2000 1998, Salvador. Resumos... Brasília, DF: Sociedade Botânica do Brasil, 2000. p. 200.

RAMOS, E.O.L.; IMAÑA-ENCIMAS, J. Fitossociologia da mata de galeria estivinha no Parque Nacional Chapada dos Veadeiros. In: CONGRESSO E EXPOSIÇÃO INTERNACIONAL SOBRE FLORESTAS, 6., 2000, Porto Seguro. Resumos Técnicos... Rio de Janeiro: Instituto Ambiental Biofera, 2000. p. 306.
SILVA, J.G.; SENTELHAS, P.C. Diferença de temperatura mínima do ar medida no abrigo e na relva e probabilidade de sua ocorrência em eventos de geada no Estado de Santa Catarina. Revista Brasileira de Agrometeorologia, v. 9, n.1, p. 9-15, 2001.

SOERIANEGARA, I.; LEMMENS, R.H.M.J. Calophyllum L. Plant Resources of South-East Asia, v. 5, n. 1, p. 114-119, 1993.

SOUZA, M.H.; MAGLIANO, M.M.; CAMARGOS, J.A.A. Madeiras tropicais brasileiras. Brasília DF: Ibama, Laboratório de Produtos Florestais, 1997. $152 \mathrm{p}$.

STANNARD, B.L. Flora of the Pico das Almas: Chapada Diamantina, Bahia, Brazil. Kew: Royal Botanical Gardens, 1995. 853 p.

THORNTHWAITE, C.W. An approach toward a rational classification of climate. Geographical Review, v. 38, p. 55-94, 1948.

UNITED STATES GEOLOGICAL SURVEY. Survey National Mapping Division. Global 30 arc second elevation data. 1999. Disponível em: $<$ http://edcwww.cr.usgs.gov/landdaac/gtopo30/ gtopo30.html>. Acesso em: 10 jul. 2011.

WREGE, M.S. et al. Atlas climático da região Sul do Brasil: estados do Paraná, Santa Catarina e Rio Grande do Sul. Pelotas: Embrapa Clima Temperado, 2011. v. 1, 332 p.

et. al. Pinus tropical com potencial para uso em plantios comerciais no Brasil. Revista do Instituto Florestal, v. 26, p. 137-145, 2014. 